\title{
Teaching renewed Multimedia subjects at the University of Pannonia
}

\author{
Cecilia Sik-Lanyi, Tibor Guzsvinecz, László Czúni \\ University of Pannonia, Department of Electrical Engineering and Information Systems, Veszprém, Hungary \\ lanyi@almos.uni-pannon.hu, guzsvinecz.tibor@virt.uni-pannon.hu, czuni.laszlo@virt.uni-pannon.hu
}

\begin{abstract}
The article shows the evolving of subjects connected to multimedia based on the training requirements, the curriculum of each subject and the teaching experiences of the first two semesters at the Faculty of Information Technologies of University of Pannonia.
\end{abstract}

Keywords: Multimedia, Training requirements, BA, Advanced vocational qualification, Teacher training

\section{INTRODUCTION}

According to the training and outcome requirements of higher education trainings (KKK-Hungarian abbreviation) in Hungary the curriculum had to be changed in the last few years. As a result the 5 credits subject "Multimedia" for computer science engineers has been deleted and the 2 credits "Multimedia in education" took its place for the teacher training students before the changeover to Bologna Process. In the current system a 2 credits subject called "Introduction to multimedia" has been introduced for the advanced vocational qualification students and a subject with the same name for the future IT teachers and business informatics engineers.

\section{A. Congruity to training and outcome requirements}

Based on the new training outcomes and requirements the extant subjects had to be supervised and new subjects to be suggested.

The training outcomes and requirement of the advanced vocational qualification prescribes in the area of obtainable skills the following:

The attendee possesses the knowledge of specializationspecific devices to select and complete the tasks correspondingly to the specification- at the following areas: computer graphics, expert systems, multimedia applications, numerical computation skills, geoinformatics, information security, database management systems.

Additional regulations only at multimedia specialization that:

- The attendee is able to create multimedia materials for the application of skills connected to multimedia.

- Is able to use and apply the prevailing multimedia development devices.
- Is able to create digital pictures, for vector- and pixel graphic editing of pictures, to create digital audio recording, sound editing,

to digitally record and edit simple video productions and create animations.

- Is able to choose from multimedia authorial systems.

- Is able to apply the multimedia design, editor and typography skills in a creative way.

- Is able to compose presentations and e-learning materials individually or in a team.

- Is able to use media-communication toolkit.

- Is able to test multimedia system elements, processes, functions and visualization.

- Is able to develop display of multimedia elements and applications (graphics, design, interactions) and the use of graphical programs.

- Is able to integrate the source materials into a specified system, to create, test and accomplish corrections on the prototype of the multimedia product.

- Is able to specify the device context and requirements for the working of application.

Out of the information technology BA departments only the computer scientist students are required to have knowledge about the specific IT devices for the choice of the tools and accomplishment of tasks, especially correspondingly to the specification of the student - in the following fields: computer graphics, expert systems, multimedia applications, numerical computation skills, geoinformatics, information security, database management systems.

While there had been the "Multimedia" and the "Virtual Reality and it's applications" courses for 5-5 credits at the University of Pannonia after introducing the Bologna Process only "Virtual Reality and it's applications" course has remained in the syllabus for 4 credits. The old courses and the syllabus had to be checked and new courses to be introduced based on the training and outcome requirements. In this case the first step was to check and adapt the syllabus of the existing courses and then insert the new courses into them. It also needed to be checked whether the new courses of the higher-level vocational training can be taught together with the courses of the basic degree. 
We have found out that the higher-level vocational training course cannot be taught together with the "Multimedia" course in the basic degree since in the vocational training the syllabus of the course contains more practical knowledge.

The net of courses in the field of multimedia and virtual reality are presented in the following section.

\section{B. Planned net of courses}

Fig. 1. shows the first version of the planned net of courses.

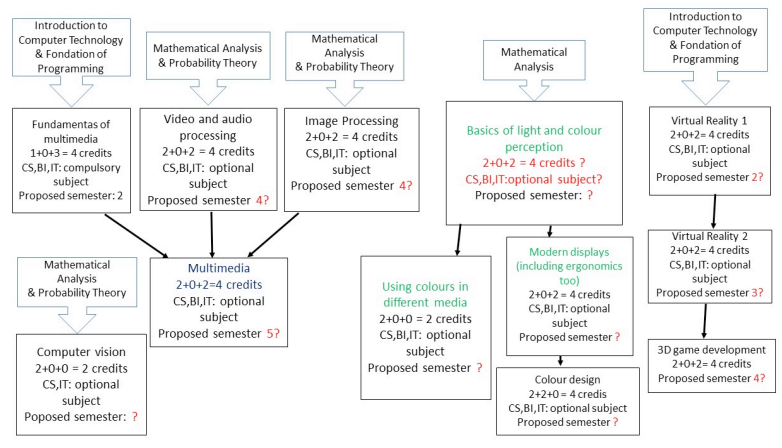

Fig. 1. First version of the planned net of courses

After the consultation with the teachers of the other courses the second version of the planned net of courses has been created. (Fig. 2.).

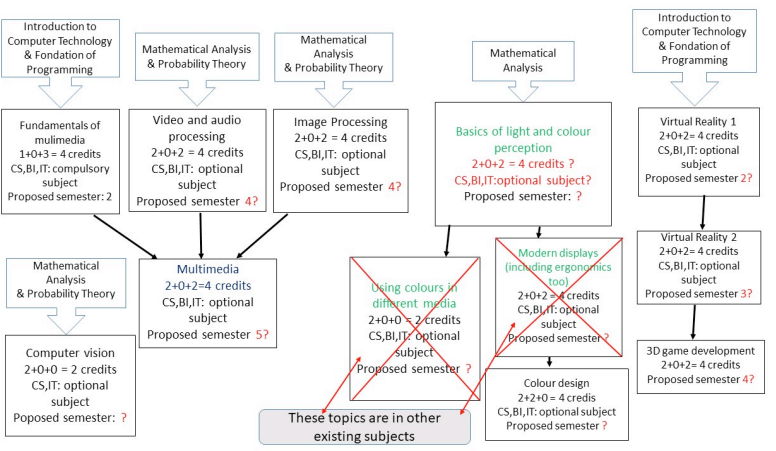

Fig. 2. Second version of the planned net of courses

The other figures (Fig. 3-4-5) show the final net of proposed courses of the basic degree departments.

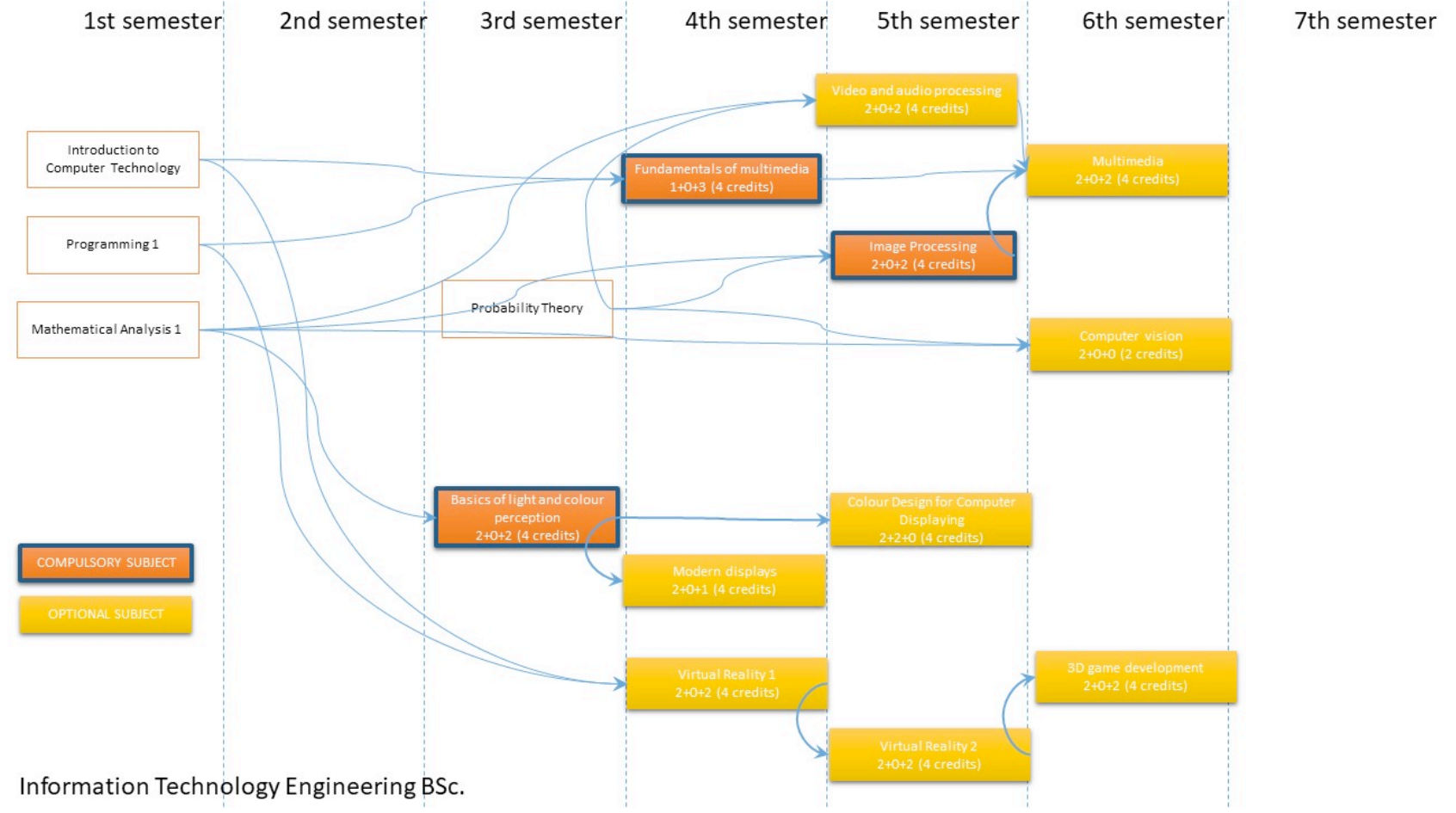

Fig. 3. Basic degree Information Technology engineers' media-informatics proposed net of courses 


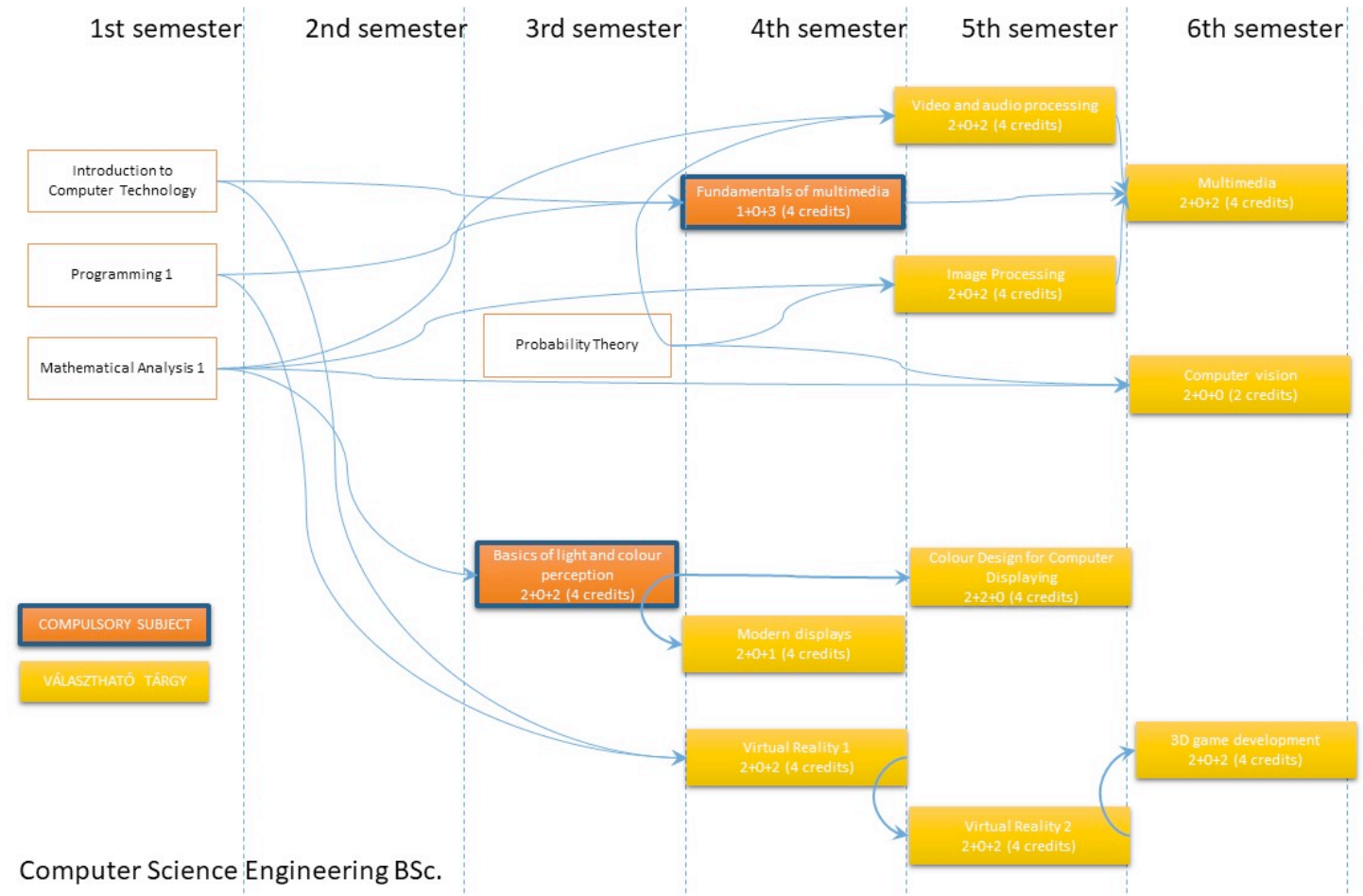

Fig. 4. Basic degree Computer Scientists' media-informatics proposed net of courses

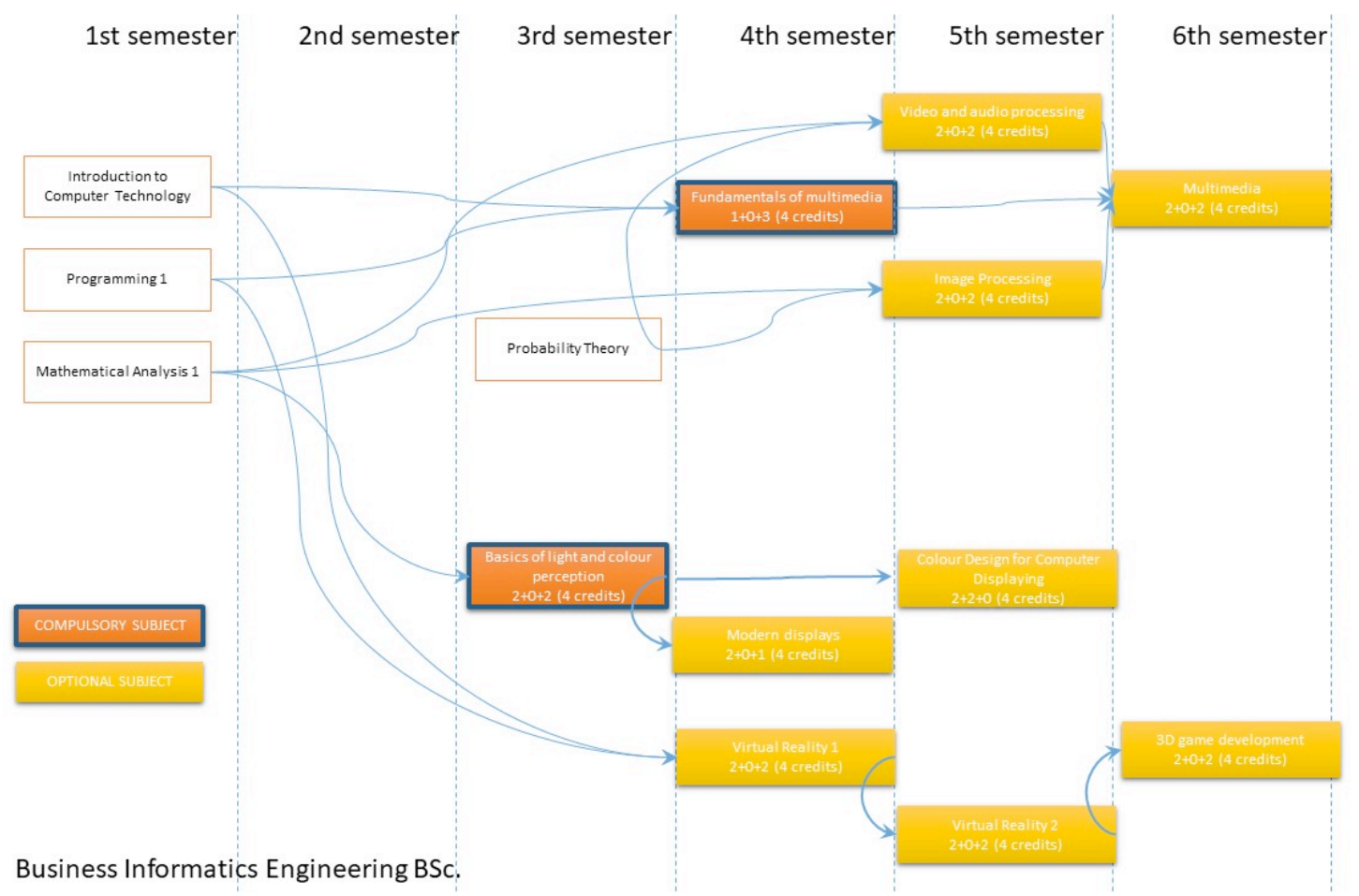

Fig. 5. Basic degree Business Informatics engineers' media-informatics proposed net of courses 


\section{COURSE: INTRODUCTION TO MULTIMEDIA}

Educational aim of "Introduction to Multimedia": The student should be able to create and edit different source materials (texts, audio, motion picture and still image, graphics, and animation) and to determine the needed software and hardware devices' parameters and supplies.

\section{A. Semestral educational tasks in weekly breakdown}

The syllabus of the higher level vocational training course contains more practical skills (Table 1.) than the Multimedia course for the basic degree departments.

TABLE 1.

SEMESTRAL EDUCATIONAL SYLLABUS

\begin{tabular}{|c|c|}
\hline Week & Syllabus \\
\hline 1. & $\begin{array}{c}\text { Introductions, definitions, fields of application, hardware, } \\
\text { software, typography }\end{array}$ \\
\hline 2. & Representation and transformation of images \\
\hline 3. & Image filtering and editing \\
\hline 4. & Basic terms and devices of computer graphics \\
\hline 5. & Basic terms and devices of audio editing \\
\hline 6. & Basic terms and devices of video editing \\
\hline 7. & Team work, practice: image processing \\
\hline 8. & Creating animations \\
\hline 9. & Creating animations \\
\hline 10. & Semestral break \\
\hline 11. & Theoretical examination, team work, practice \\
\hline 12. & Team work, practice: creating animation \\
\hline 13. & Team work, practice: creating animation \\
\hline 14. & $\begin{array}{l}\text { Practical examination, presenting of works of the teams, } \\
\text { presentations }\end{array}$ \\
\hline
\end{tabular}

System of examination and evaluation: 2 pieces of individual assignment, 2 classroom tests, oral presentation (presenting the work of the team).

The literature recommended for students are indicated in the reference list.

\section{B. Sample for written examination questions}

Sample questions for introductory skills:

1. What is the definition of multimedia?

2. What do we mean by typography?
Ren'py questions:

3. Define a character in ADV mode and Ren'py program code!

4. Initialize a picture with Ren'py program code!

5. Display the previous picture on the screen using Ren'py program code!

6. Which is the label that needs to be added in order to start the visual novella?

7. On how many parts of the screen is it able to place a character? Which are these exactly?

8. Initialize a bool and an integer variable with Ren'py program code!

Pencil2D questions:

9. How many type of layers can be created in the application in the case of creating animations? Which are these? What can be done on each of the layers?

10. By which color channel can be the transparency adjusted?

Image processing, audio- and video editing sample questions:

11. Describe the imaging of the convex lens (by drawing) and the optical basic equation!

12. What does the histogram depict, how does the histogram of an underexposed image look like?

13. What are the main segments of a film?

14. What does the sampling law ascertain?

15. What are the frequency sensing limits of human ears?

16. How does Dolby SVA work?

\section{Example for exam questions}

Definition of multimedia, its application, multimedia design software

Typography

Creating animations by Ren'py software

Creating animations by Pencil2D software

Basic terms in connection with colors

Image editing

Video editing

Audio editing

\section{Examples for practical assignment tasks}

Practical examples:

- $\quad$ Create an animated invitation card for an actual event: birthday, name day, university days, etc. 
- Illustration of additive and subtractive color mixing: Create two images with the help of layers and save the pictures in JPG (Summarizing, Only Dimming). It is practical to start with the additive method and copy the CMY colors.

- $\quad$ Mix a $50 \mathrm{~Hz}$ sine signal to a previously recorded speech, then filtrate it with different frequency filters (illustrate the spectrum before and after filtration) .

\section{COURSE: BASICS OF A MULTIMEDIA}

The educational aim of "Basics of Multimedia" course are the same as in the case of higher level vocational training course, but associated with more theoretical knowledge.

\section{A. Semestral educational tasks in weekly breakdown}

Table 2. shows the syllabus of basic degree course "Basics of Multimedia".

TABLE 2.

SEMESTRAL EDUCATIONAL SYLLABUS

\begin{tabular}{|c|c|}
\hline Week & Syllabus \\
\hline 1. & $\begin{array}{c}\text { Introduction, definitions, application areas, the role of } \\
\text { hardware and software }\end{array}$ \\
\hline 2. & Readability and aesthetics of texts, typography skills \\
\hline 3. & $\begin{array}{l}\text { Light as an image producer, basic mechanism of human } \\
\text { sight, image processing, by convex lens, optical basic } \\
\text { equation, E-value, context of depth of focus }\end{array}$ \\
\hline 4. & $\begin{array}{l}\text { Perception of image, change of the histogram, contrast, } \\
\text { lucidity and white balance of the picture; Sampling of } \\
\text { images, filtering of images in the pixel and frequency } \\
\text { space; Basic operations of image editing }\end{array}$ \\
\hline 5. & Basic definitions and devices of computer graphics \\
\hline 6. & $\begin{array}{l}\text { Basic physical qualities of sound propagation, basics of } \\
\text { acoustics; Limits of human hearing; Recording sounds, } \\
\text { sound systems, audio coding methods and standards; Basic } \\
\text { operations of audio editing }\end{array}$ \\
\hline 7. & $\begin{array}{l}\text { Analog and digital television and video standards; } \\
\text { Principles of image and video coding; Embossment of } \\
\text { image information; Basic operations of video editing }\end{array}$ \\
\hline 8. & $\begin{array}{l}\text { Theoretical and practical skills of creating animations: } \\
\text { design }\end{array}$ \\
\hline 9. & $\begin{array}{c}\text { Theoretical and practical skills of creating animations: } \\
\text { types of animations }\end{array}$ \\
\hline 10. & $\begin{array}{l}\text { Theoretical and practical skills of creating animations: } \\
\text { interactivity }\end{array}$ \\
\hline 11. & Theoretical examination, team work, practice \\
\hline 12. & Team work, practice \\
\hline 13. & Team work, practice \\
\hline 14. & Practical examination, presenting of works of the teams \\
\hline
\end{tabular}

System of examination and evaluation: 2 pieces of individual assignment, 2 classroom tests, oral presentation (presenting the work of the team).

The literature recommended for students are indicated in the reference list.

\section{B. Sample questions for written examination}

1. What is the definition of multimedia and what are its fields of application?

2. Describe the main development steps of typography!

3. Define a text by Ren'py program code!

4. Initialize and display a picture on screen using Ren'py program code!

5. Initialize a bool and an integer equation by Ren'py program code!

6. How much type of layers can be created in the application in the case of creating animations? Which are these? What can be done on each of the layers?

7. Which color systems are practical to use?

8. By which color channel can be the transparency adjusted?

9. What is Onion Skin? How much can the application handle?

10. Describe the imaging of the convex lens (by drawing) and the optical basic equation! How can you define depth of focus, and what affects it?

11. What does the histogram depict, how does the histogram of an underexposed image look like? How could you automatically correct the contrast of the image?

12. What are the main segments of a film? How can the limits of segments be detected?

13. What does the sampling law ascertain, where does it have function in video making?

14. What are the frequency sensing limits of human ears? How can the 3D effect be boosted by audio methods?

15. How does Dolby SVA work? What kind of audio sound systems do you know?

16. Describe the typical basic steps of wavefunctionbased still image compression.

17. Describe the basic steps of video compression.

18. Describe an embossing algorithm.

\section{Sample question for examination}

Definition of multimedia, its application, multimedia design software

Image processing: representation, transforming and filtering of images

Audio editing skills

Video editing skills

Basics of computer graphics skills

Types and characteristics of animations

Actualization of interactivity 


\section{Examples for practical assignment tasks}

Practical examples:

Practical assignment tasks (examples):

- Create an interactive animation for an actual event, e.g. university days. The animation should contain sound, and pasted video. The interactivity must be made by scripts.

- $\quad$ Image processing task: Create two versions of a photorealistic image: a car is moving on the road. In the first case the car should be out-of-focus, while in the other case the car should be sharp and the background out-offocus., as if the photo was taken of a moving car. Take care about white balance and the setting of contrast rate.

- Video and audio assignment task: Creating video for Ben Sollee-Copper and Malachite.by using Filmora, Audacity and Gimp. The "scenario" should be attached (when and what kind of editing has been done). Using the following effects is required: Headline, dissolving of images/videos; enlarging, rotating, blurring (backwards) of the images during playtime; old film effect; cutting and placing the image on the background; "radio" effect of sound; increasing volume of sound.

\section{EDUCATIONAL EXPERIENCES OF MULTIMEDIA COURSE FOR CORRESPONDENCE TRAINING STUDENTS}

Since in the correspondence training there had been less lectures the skills to be learnt must have been taught in a compact form. The course was taught for students of teacher training, who already have a degree. The creation of animations has been taught using Blender 3D modeling software based on their syllabus.

At the end of the semester the students were asked about their opinion: what did they like, what were they satisfied with, what other topics should be added, or what changes would they recommend?

The main problem in the case of correspondence training students was that most of the lectures were used for theoretic tasks. They thought it might be decreased, since they can learn the theoretic parts from other sources at home, and they would prefer more practical training. Besides, the assignment tasks took a lot of time, because there was only a limited time to practice with the software needed for the actualization of the task.

\section{CONCLUSION}

In the article the creation of new courses related to multimedia. These courses are for the higher level vocational training students, the basic degree students and the university-level teacher training students. The renewed courses had been taught for two semesters, first for the vocational training students, then in the second semester of 2017/2018 school year for the correspondence training students. We have asked the opinion of students about the course. At the "Multimedia in Education" conference [6] in 2018 besides the syllabi, the educational experiences and the opinion of students some of the assignment tasks have also been presented.

\section{REFERENCES}

[1] Ze-Nian Li, Mark S. Drew, Jianchuan Liu: Intorduction to Multimedia, Springer Kiadó

[2] Czúni-Takács: Képi információ mérése, Typotex Kiadó

[3] Ralf Steinmetz: Multiméda, Springer Kiadó

[4] Andreas Holzinger: A multimédia alapjai, Kiskapu Kiadó

[5] Tay Vaughan: Multimédia, Pánem Kiadó

[6] Sikné Lányi Cecília, Guzsvinecz Tibor, Czúni László: Megújult multimédia tárgyak oktatása a Pannon Egyetemen, XXIV. Multimédia az oktatásban konferencia, Budapest, 2018. máj. 31 - jún. 02, Budapest, 204-209. old. ISBN: 978-615-5036-13-2, DOI: 10.26801/MMO.2018.1.024 